Published in final edited form as:

Breast Cancer Res Treat. 2009 October ; 117(3): 603-609. doi:10.1007/s10549-009-0332-2.

\title{
Immediate versus delayed zoledronic acid for prevention of bone loss in postmenopausal women with breast cancer starting letrozole after tamoxifen-N03CC
}

\author{
Stephanie L. Hines \\ Mayo Clinic Jacksonville, Jacksonville, FL 32224, USA \\ Betty Mincey \\ Private Practice, Jacksonville, FL, USA \\ Todor Dentchev \\ Altru Health Systems, Grand Forks, ND 58201, USA \\ Jeff A. Sloan \\ Mayo Clinic Foundation, Rochester, MN 55905, USA \\ Edith A. Perez \\ Mayo Clinic Jacksonville, Jacksonville, FL 32224, USA \\ David B. Johnson \\ Wichita Community Clinical Oncology Program, Wichita, KS 67214-3882, USA \\ Paul L. Schaefer \\ Toledo Community Hospital Oncology Program CCOP, Toledo, OH 43623, USA \\ Steve Alberts \\ Mayo Clinic Foundation, Rochester, MN 55905, USA \\ Heshan Liu \\ Mayo Clinic Foundation, Rochester, MN 55905, USA \\ Stephen Kahanic \\ Siouxland Hematoloey-Oncology Associates, Sioux City, IA 51105, USA \\ Miroslaw A. Mazurczak \\ Sioux Community Cancer Consortium, Sioux Falls, SD 57105, USA \\ Daniel A. Nikcevich \\ Duluth CCOP, Duluth, MN 55805, USA \\ Charles L. Loprinzi \\ Mayo Clinic Foundation, Rochester, MN 55905, USA
}

\section{Abstract}

Postmenopausal women with breast cancer (BC) are at increased risk for bone loss.

Bisphosphonates improve bone mineral density (BMD) in normal postmenopausal women. The purpose of this study was to determine if immediate treatment with zoledronic acid preserves BMD in postmenopausal women with BC starting letrozole after tamoxifen. Postmenopausal women with $\mathrm{BC}$ completing tamoxifen were treated with daily letrozole $2.5 \mathrm{mg} /$ vitamin D 400 
I.U., calcium $500 \mathrm{mg}$ twice daily and were randomized to upfront or delayed zoledronic acid $4 \mathrm{mg}$ every 6 months. Patients in the delayed arm were only given zoledronic acid if they developed a post-baseline BMD T score $<-2.0$ or had a fracture. The primary endpoint was the mean percent change in lumbar spine (LS) BMD at 1 year. About 558 women enrolled; 395 provided 1 year BMD data. The upfront arm experienced a mean change of $+3.66 \%$ in LS BMD versus $-1.66 \%$ for the delayed group $(P<0.001)$. Changes at the femoral neck/total hip were also greater for the upfront versus delayed arms $(P<0.001 ; P<0.001)$ with differences persisting at 2 years. Patients in the delayed arm were more likely to experience a clinically meaningful $5 \%$ loss of BMD at all sites versus the upfront zoledronate group. Patients in the upfront arm were slightly more likely to report limb edema, fatigue, fever, nausea and jaw osteonecrosis(1\%). Upfront zoledronic acid prevents bone loss in postmenopausal women with $\mathrm{BC}$ starting letrozole after tamoxifen.

\section{Keywords}

Breast cancer; Aromatase inhibitor; Bone loss; Zoledronic acid

\section{Introduction}

Postmenopausal women with breast cancer are at increased risk for osteoporosis as annual rates of bone loss increase in the first few years after menopause. Estrogen, with or without progesterone, may prevent this decline in bone mineral density (BMD) and the subsequent progression to osteoporosis. The effect of estrogen is mediated through a reduction in osteoclast activity by increasing osteoclast apoptosis and reducing osteoclast differentiation [1], This treatment, however, is generally not recommended in breast cancer patients because of the strong hormonal influence derived from the estrogen and progesterone receptors that are found in most breast malignancies.

Selective estrogen receptor modulators (SERMs) like raloxifene may be used for the prevention of osteoporosis in normal postmenopausal women or those at high risk for breast cancer. However, the role of raloxifene in postmenopausal women with a history of breast cancer has not been defined. Tamoxifen, the most commonly used SERM for the treatment of breast cancer, has been reported to improve BMD in postmenopausal women by an annual rate of $1.2 \%$ in the spine and $1.7 \%$ at the hip [2].

Several trials have demonstrated the efficacy of aromatase inhibitors as adjuvant hormonal therapy for postmenopausal breast cancer patients, either after initial therapy with tamoxifen or in place of tamoxifen [3-8]. Aromatase inhibitors (AI) prevent aromatase, an enzyme found in peripheral adipose tissue, from converting androgens into estrogen. While AIs improve disease free survival in hormone receptor positive breast cancer patients compared to tamoxifen, decreases in BMD occur with this intervention, with an estimated 2 year bone loss at the lumbar spine of $4-5 \%$ and at the hip of about $4 \%[9,10]$.

Women who begin an aromatase inhibitor following initial therapy with tamoxifen are thus at risk for bone loss both from the withdrawal of the protective effect of tamoxifen and from the negative effect of the AI itself. Therefore, a need exists for a treatment that will prevent the bone loss that may be associated with the use of AIs and to increase BMD in postmenopausal women with breast cancer.

Bisphosphonates have been approved in the United States for the prevention and treatment of osteoporosis in normal postmenopausal women as well as for the management of bone lesions in women with advanced breast cancer. Zoledronic acid is a highly potent nitrogencontaining bisphosphonate that is an effective inhibitor of osteoclast-mediated bone 
resorption. In normal postmenopausal women, it increases BMD by 4-5\% at the lumbar spine and 3-4\% at the femoral neck, compared to placebo, and is effective with intermittent administration [11]. It also bypasses the potential disadvantages of the oral route used by other bisphosphonates, which may include poor bioavailability, gastrointestinal intolerance, and inadequate compliance. While zoledronic acid may preserve the BMD of postmenopausal women with breast cancer who are scheduled to begin therapy with an aromatase inhibitor after initial tamoxifen therapy, the efficacy and safety of this intervention had not previously been evaluated in this setting.

\section{Materials and methods}

This study was conducted by the North Central Cancer Treatment Group (NCCTG) after approval by the National Cancer Institute (NCI) and the local Institutional Review Boards from participating sites. Informed written consent was obtained from all participants prior to enrollment. The study was primarily funded by the NCI, with supplemental funding provided by Novartis, who had no involvement in the conduct of the study.

\section{Study population}

Eligible study participants were postmenopausal women with a history of Stage I-IIIa, estrogen and/or progesterone receptor positive breast cancer who had completed $\mathbf{6} 6$ years of tamoxifen, and had no evidence of recurrent or metastatic disease. Postmenopausal status was defined as women $>55$ years with cessation of menses, women $\$ 55$ years with spontaneous cessation of menses $>1$ year or women with bilateral oophorectomy. Women $\$ 55$ years, with no spontaneous menses for $<1$ year but with postmenopausal estradiol levels were also eligible. Patients must have been accessible for follow-up, must have had a life expectancy of $\geq 5$ years, and must have had an ECOG performance score of 0-2. Laboratory studies obtained within 30 days prior to randomization must have included a white blood cell count of $\geq 3,000\left(3.0 \times 10^{9} / 1\right)$ or granulocyte count of $\geq 1,500\left(1.5 \times 10^{9} / 1\right)$, platelet count of at least 100,000 $\left(100 \times 10^{9} / 1\right)$, alkaline phosphatase no more than three times the upper limit of normal, AST (asparate aminotransferase) no more than three times the upper limit of normal, and creatinine of $<2.0 \mathrm{mg} / \mathrm{dl}$. Oral bisphosphonates must have been discontinued $>3$ weeks prior to randomization.

Exclusion criteria included clinical or radiological evidence of recurrent or metastatic disease before randomization, clinical or radiological evidence of existing fracture in the lumbar spine (LS) and/or total hip (TH), history of fracture with low-intensity or no associated trauma, any endocrine therapy (including estrogen) within the last 12 months other than tamoxifen, insulin, oral hypoglycemics, thyroid hormone, or steroid inhalers. Treatment was not allowed with systemic corticosteroids within the last 12 months (other than short-term corticosteroid therapy as defined by doses for $<2$ weeks in the preceding 6 months), parathyroid hormone for $>1$ week, systemic sodium fluoride for $>3$ months within the preceding 2 years or other current treatment with drugs known to affect the skeleton (i.e. calcitonin, mithramycin, or gallium nitrate) within 2 weeks prior to randomization. Also excluded were prior treatments with intravenous bisphosphonates, prior AI therapy, prior

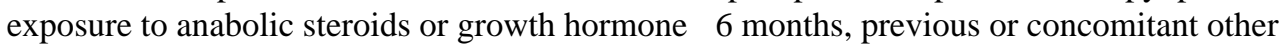
malignancy $\mathbf{5}$ years (except adequately treated basal or squamous cell carcinoma of the skin and in situ carcinoma of the cervix), uncontrolled infections, diabetes mellitus, or thyroid dysfunction. Additional exclusions were uncontrolled seizure disorders, baseline LS or femoral neck (FN) BMD T score worse than -2.0, treatment with systemic investigational drugs and/or devices $\leq 30$ days or topical investigational drugs $\leq 7$ days prior to randomization, mental illness that precluded the patient from giving informed consent, hypercalcemia, hypocalcemia, or known hypersensitivity to zoledronic acid or other bisphosphonates, letrozole, calcium or vitamin D. 


\section{Study design}

This was a two-arm, randomized, phase III open-label trial designed to assess whether upfront zoledronic acid would prevent bone loss in postmenopausal women with breast cancer initiating therapy with an AI after tamoxifen. All patients were assigned to take letrozole $2.5 \mathrm{mg}$ daily, vitamin D 400 international units daily, and calcium $500 \mathrm{mg}$ twice daily. Patients were randomized to receive zoledronic acid upfront versus zoledronic acid being delayed until either a post-baseline T score of $<-2.0$ at either the LS or FN was obtained, a clinical fracture unrelated to trauma was found, or an asymptomatic fracture was discovered. All doses of zoledronic acid were provided intravenously over $15 \mathrm{~min}$ at a dosage of $4 \mathrm{mg}$. Doses were given every six months for 5 years or until breast cancer recurrence. The dosage of zoledronic acid was adjusted for a creatinine clearance $<60 \mathrm{ml} /$ min, such that patients with a creatinine clearance of 50-60 ml/min received $3.5 \mathrm{mg}$ zoledronic acid, those with a creatinine clearance of $40-49 \mathrm{ml} / \mathrm{min}$ received $3.3 \mathrm{mg}$ zoledronic acid, and those with a creatinine clearance of 30-39 received $3.0 \mathrm{mg}$ zoledronic acid. Patients were to receive letrozole for 5 years or until breast cancer recurrence. The use of ancillary treatments including short-term corticosteroids were allowed, except for treatments that would be expected to affect osteoclast activity, additional anticancer therapy, other bisphosphonates (other than the study medication), calcitonin, sodium fluoride, parathyroid hormone, tibolone, or any investigational drag or device (excluding study medications). Patients were stratified by duration of prior tamoxifen, time since tamoxifen use, prior adjuvant chemotherapy, and baseline BMD T scores.

The primary endpoint was the mean intra-patient percent change in total LS BMD from baseline to 12 months. Secondary endpoints included the mean change in LS BMD from baseline to $24,36,48$, and 60 months post-study entry. The incidence of osteoporosis on each treatment regimen was calculated. Osteoporosis was defined as a standardized BMD score of at least 2.5 standard deviations below the age and gender-specific normal at any measured site. Since a 5\% difference in intra-patient BMD scores from baseline was defined as clinically significant and indicative of an important loss of bone density, the incidence of this event in each treatment arm was calculated. Hip BMD was compared across treatment arms in the same manner as described for LS BMD. The incidence of bone fractures was also compared across treatment groups, as was the frequency and severity of toxicity reported, using the NCI Common Toxicity Criteria (CTC).

The change in bone density was assessed by measuring BMD by dual-energy $\mathrm{x}$-ray absorptiometry (DEXA) devices at the LS and FN at baseline and annually thereafter out to 5 years. Initial X-rays of the lumbar and thoracic spine were performed at baseline to exclude patients with evidence of fracture. Repeat $\mathrm{x}$-rays or bone scans were performed during the course of the patient's participation to confirm evidence of clinical fracture, or at month 36 if there was no clinical evidence of fracture. Patients were assessed at each visit for disease progression. Further testing to confirm progression was performed as clinically indicated and patients were discontinued from study if they had disease progression.

\section{Statistical analysis}

Analysis of the primary endpoint was carried out by comparing the average values of the intra-patient change in LS BMD between the two treatment arms with the Wilcoxon Rank Sum test. A two-sample $t$-test with 250 patients per treatment arm was estimated to have $90 \%$ power to detect a difference of $2.9 \%$ in the average percent change from baseline in LS BMD between the treatment groups with a 5\% Type I error rate. The sample size was inflated by $10 \%$ to account for missing data, to try to produce 500 evaluable cases for the primary endpoint. Regression models used to incorporate covariates produced results consistent with the primary analysis. The average change in the LS BMD at years $2-5$, as 
well as the average change in the FN and total hip (TH) BMD at years 1-5 between the two treatment arms were compared via two-sample $t$-tests analogous to the primary analysis. The annual incidence rates for osteoporosis, bone fractures, and a clinically significant decrease in BMD between the two treatment arms was compared via chi-square testing. Toxicity rates were compared across treatment groups using chi-square testing.

\section{Results}

Between February, 2005 and March, 2006, 558 patients were enrolled. There were seven cancellations, five on the upfront arm and two on the delayed arm. About 120 patients went off study for reasons which included patient refusal, adverse events, disease progression, and death. Of these, 34 provided BMD data at baseline and 1 year. One patient on the upfront arm did not provide usable BMD data. This left 395 patients with data available for the primary analysis (one year change in BMD at the LS). A total of 310 provided BMD data at 2 years. Figure 1 depicts the flow of data. Patients ranged in age from 36 to 88 years with a median age of 59 years. The distribution of baseline factors by treatment arm is outlined in Table 1.

\section{Bone mineral density results}

The upfront zoledronic acid arm had a statistically significantly higher average change (mean 0.04 vs. $-0.02 ; P<0.001$ ) and average percent change (mean $3.66 \%$ vs. $-1.66 \% ; P<$ 0.001 ) in LS than the delayed zoledronic acid arm (Table 2). This difference between treatment arms was maintained at 2 years, with the change in LS BMD (mean 0.05 vs. $-0.03 ; P<001)$ and percent change $(4.94 \%$ vs. $-2.28 ; P<0.001)$ showing a statistically significant higher value in the upfront zoledronic acid arm.

At the FN, the upfront zoledronic acid arm had significantly higher values for both change and percent change at both 1 and 2 years (Table 3) than the delayed arm. The average change in TH BMD and percent change at 1 and 2 years post baseline were also significantly higher in the upfront treatment arm than the delayed arm.

A 5\% intra-patient decline in BMD at 1 year was defined as a clinically meaningful loss of bone density. The upfront zoledronic acid arm had a statistically significant lower incidence of a clinically meaningful loss of bone density at the LS, FN or TH than did the delayed arm (Table 4). There were fewer reports of osteoporosis (defined as a standardized BMD score of at least 2.5 standard deviations below the age and gender-specific norm at any measured site) in the upfront treatment arm than the delayed arm (0 vs. 4), although this was not a statistically significant difference. During the first year, 19 patients (7\%) in the delayed arm started zoledronic acid while 32 (12\%) started zoledronate within the first 2 years.

\section{Toxicity}

At 6 and 12 months, there was a significant difference in the reported incidence of fever between the two treatment arms (higher incidence in the upfront group), consistent with this known short term toxicity after a dose of zoledronate. During the first 6 months, (Table 5) there was also a difference in the reported incidence of nausea and vomiting (higher in the upfront group). At 1 year, the maximum grade of creatinine, limb edema, fatigue, fever, and nausea was higher in the upfront group than the delayed group (Table 6). For all other adverse events, there was no significant difference between treatment arms.

One patient on the upfront arm was diagnosed with osteonecrosis of the jaw (ONJ) within 8 weeks of her first dose of zoledronic acid. This diagnosis was made by an oral surgeon who saw the patient for evaluation of "exostoses" that had been present for several weeks. 
Several areas of exposed bone were noted. She was treated with antibiotics and advised to avoid using her lower denture. Complete resolution occurred within 5 months. There were no reports of $\mathrm{ONJ}$ in the delayed arm.

\section{Discussion}

This randomized clinical trial demonstrated that upfront treatment with zoledronic acid prevented bone loss in postmenopausal women with breast cancer treated with letrozole after patients had received tamoxifen. The patients who did not receive upfront zoledronic acid lost a mean $1.66 \%$ bone density at the LS at 1 year. However, upfront therapy with zoledronic acid not only prevented this bone loss but was associated with an increase of $3.66 \%$ at the LS at 1 year. This $5 \%$ difference in BMD at 1 year between the two treatment arms is considered clinically meaningful, since a loss of $10 \%$ BMD may double the fracture risk. Although a comparison of fracture rates was a secondary endpoint in this study, at this early time point, there are not a sufficient number of fractures in either group to provide a clinically reliable statistical analysis. However, all other endpoints used in the trial for the purposes of sensitivity analysis produced consistent results regarding the finding that upfront treatment with zoledronic acid provides a statistically significant improvement in BMD at 1 year. Notably, patients treated with delayed zoledronic acid were between two and seven fold more likely to experience a clinically meaningful loss of bone density compared to the immediate treatment group (Table 4).

The results from this study are consistent with previously published reports that bone density declines in postmenopausal women who begin therapy with an AI $[9,10]$, an effect that may be augmented by the withdrawal of the protective effect of tamoxifen. This appears to be because aromatase inhibitors suppress the anti-resoiptive effect of estrogen on osteoclasts, an effect that can be overcome by inhibition of osteoclast activity with zoledronic acid, supported by the results from this study. The prevention of bone loss with upfront zoledronic acid therapy is also consistent with results from the Z-FAST trial, which found that BMD in the LS was $4.4 \%$ higher in women, at one year, treated with upfront zoledronic acid than those randomized to delayed therapy [12].

Changes in the BMD may serve as a marker of fracture risk [13] such that improvements in bone density over time may reduce the fracture risk. Although an accurate assessment of the effect of upfront zoledronic acid on fracture risk cannot be made with either this study or the results from the Z-FAST trial, this may be due to a relatively short follow-up time. Ongoing analyses of fracture rates will evolve with longer duration of follow-ups in both of these studies. However, previous studies of bisphosphonate therapy in postmenopausal women, including studies of alendronate, risedronate, and zoledronic acid [14-16] have shown a reduction in osteoporosis-related fracture rates that corresponds to an increase in BMD.

Toxicity profiles between treatment arms indicated that as many as $5 \%$ of patients might experience some toxicity from zoledronic acid, although the toxicities were generally mild and there were no differences in the incidence rates of severe toxicity at one-year of followup.

ONJ has been recognized as a potential complication from chronic intravenous or high dose bisphosphonate therapy, including zoledronic acid. In this study, one patient, randomized to the upfront arm, experienced ONJ within the first 2 months of treatment. While this adverse event is likely related to the use of zoledronic acid, its occurrence so soon after a first dose of zoledronic acid is unusually rapid.

This study thus demonstrates an advantage of immediate treatment with zoledronic acid in preventing bone loss in postmenopausal women on letrozole for breast cancer. The size of 
the observed effect was sufficiently large and consistent across multiple endpoints, including measurement approach and site, such that these results should be considered to be definitive. While it could be argued that these results support the upfront use of zoledronic acid at the onset of aromatase inhibitor therapy, it could also be argued that such a recommendation should await determination of whether upfront zoledronic acid prevents bone fractures significantly better than does delayed use of this medication, if/when the patient develops significant bone loss.

\section{Acknowledgments}

This study was funded through the NCI with supplemental funding from Novartis. This study was conducted as a collaborative trial of the North Central Cancer Treatment Group and Mayo Clinic and was supported in part by Public Health Service grants CA-25224, CA-37404, CA-35431, CA-35415, CA-35103, and CA-35269. The content is solely the responsibility of the authors and does not necessarily represent the official views of the National Cancer Institute or the National Institutes of Health. This work was also supported by the following United States National Institutes of Health Grant-CA 124477 (PI Charles Loprinzi MD)

\section{References}

1. Perez EA, Weilbaecher K. Aromatase inhibitors and bone loss. Oncology. 2006; 20(9):1029-1039. [PubMed: 16986348]

2. Powles T, Hickish T, Kanis JA, Tidy A, Ashley S. Effect of tamoxifen on bone mineral density measured by dual-energy x-ray absorptiometry in healthy premenopausal and postmenopausal women. J Clin Oncol. 1996; 14(1):78-84. [PubMed: 8558225]

3. The ATAC Trialists' Group. Anastrozole alone or in combination with tamoxifen versus tamoxifen alone for adjuvant treatment of postmenopausal women with early-stage breast cancer. Cancer. 2003; 98(9):1802-1810. doi:10.1002/cncr.11745. [PubMed: 14584060]

4. The ATAC Trialists' Group. Results of the ATAC trial after completion of 5 years' adjuvant treatment for breast cancer. Lancet. 2005; 365:60-62. doi:10.1016/S0140-6736(04)17666-6. [PubMed: 15639680]

5. Goss PE, Ingle JN, Martino S, Robert JN, Muss HB, Piccart MJ, Castiglione M, Tu D, Shepherd LE, Pritchard KI, Livingston RB, Davidson NE, Norton L, Perez EA, Abrams JS, Therasse P, Palmer MJ, Pater JL. A randomized trial of letrozole in postmenopausal women after five years of tamoxifen therapy for early-stage breast cancer. N Engl J Med. 2003; 349(39):1793-1802. doi: 10.1056/NEJMoa032312. [PubMed: 14551341]

6. Coombes RC, Hall E, Gibson LJ, Paridaens R, Jassem J, Delozier T, Jones SE, Alvarez I, Bertelli G, Ortmann O, Coates AS, Bajetta E, Dodwell D, Coleman RE, Fallowfield LJ, Mickiewicz E, Andersen J, Lonning PE, Cocconi G, Stewart A, Stuart N, Snowdon CF, Carpentieri M, Massimini G, Bliss JM. A randomized trial of exemestane after two to three years of tamoxifen therapy in postmenopausal women with primary breast cancer. N Engl J Med. 2004; 350(11):1081-1092. doi: 10.1056/NEJMoa040331. [PubMed: 15014181]

7. Coates AS, Keshaviah A, Thurlimann B, Mouridsen H, Mauriac L, Forbes JF, Paridaens R, Castiglione-Gertsch M, Gelber RD, Colleoni M, Lang I, Del Mastro L, Smith I, Chirgwin J, Nogaret MJ, Pienkowski T, Wardley A, Jakobsen EH, Price KN, Goldhirsch A. Five years of letrozole compared with tamoxifen as initial adjuvant therapy for postmenopausal women with endocrineresponsive early breast cancer: update of study BIG1-98. J Clin Oncol. 2007; 25(5):486-491. doi: 10.1200/JC0.2006.08.8617. [PubMed: 17200148]

8. The Breast International Group (BIG) 1-98 Collaboratie Group. A comparison of letrozole and tamoxifen in postmenopausal women with early breast cancer. N Engl J Med. 2005; 353(26):27472757. doi:10.1056/NEJMoa052258. [PubMed: 16382061]

9. Eastell R, Hannon RA, Cuzick J, Dowsett M, Clack G, Adams JE. Effect of an aromatase inhibitor on bind and bone turnover markers: 2-year results of the anastrozole, tamoxifen, alone or in combination trial. J Bone Miner Res. 2006; 21(8):1215-1223. doi:10.1359/jbmr.060508. [PubMed: 16869719]

10. Perez EA, Josse RG, Pritchard KI, Ingle JN, Martino S, Findlay BP, Shenkier TN, Tozer RG, Palmer MJ, Shepherd LE, Liu S, Tu D, Goss PE. Effect of letrozole versus placebo on bone 
mineral density in women with primary breast cancer completing 5 or more years of adjuvant tamoxifen: a companion study to NCIC CTG MA. 17. J Clin Oncol. 2006; 24(22):3629-3635. doi: 10.1200/JC0.2005.05.4882. [PubMed: 16822845]

11. Reid IR, Brown JP, Burckhardt P, Horowitz Z, Richardson P, Trechsel U, Widmer A, Devogelaer JP, Kaufman JM, Jaeger P, Body JJ, Meunier PJ. Intravenous zoledronic acid in postmenopausal women with low bone mineral density. N Engl J Med. 2002; 346(9):653-661. doi:10.1056/ NEJMoa011807. [PubMed: 11870242]

12. Brufsky A, Harker WG, Beck JT, Carroll R, Tan-Chiu E, Seidler C, Hohneker J, Lacerna L, Petrone S, Perez EA. Zoledronic acid inhibits adjuvant letrozole-induced bone loss in postmenopausal women with early breast cancer. J Clin Oncol. 2007; 25(7):829-836. doi:10.1200/ JC0.2005.05.3744. [PubMed: 17159193]

13. Johnell O, Kanis JA, Oden A, et al. Predictive value of BMD for hip and other fractures. J Bone Miner Res. 2005; 20:1185-1194. doi:10.1359/JBMR.050304. [PubMed: 15940371]

14. Black DM, Delmas PD, Eastell R, Reid IR, Boonen S, Cauley JA, Cosman F, Lakatos P, Chung Leung P, Man Z, Mautalen C, Mesenbrink P, Hu H, Caminis J, Tong K, Rosario-Jansen T, Rrasnow J, Hue T, Sellmeyer D, Fink Eriksen E, Cummings SR. Once-yearly zoledronic acid for treatment of postmenopausal osteoporosis. N Engl J Med. 2007; 356(18):1809-1822. doi:10.1056/ NEJMoa067312. [PubMed: 17476007]

15. Cummings SR, Black DM, Thompson DE, Applegate WB, Barrett-Connor E, Musliner TA, Palermo L, Prineas R, Rubin SM, Scott JC, Vogt T, Wallace R, Yates AJ, LaCroix AZ. Effect of alendronate on risk of fracture in women with low bone density but without vertebral fractures. JAMA. 1998; 280(24):2077-2082. doi:10.1001/jama.280.24.2077. [PubMed: 9875874]

16. Harrington JT, Ste-Marie LG, Brandi ML, Civitelli R, Fardellone P, Grauer A, Barton I, Boonen S. Risedronate rapidly reduces the risk for nonvertebral fractures in women with postmenopausal osteoporosis. Calcif Tissue Int. 2004; 74:129-135. doi:10.1007/s00223-003-0042-4. [PubMed: 14648009] 


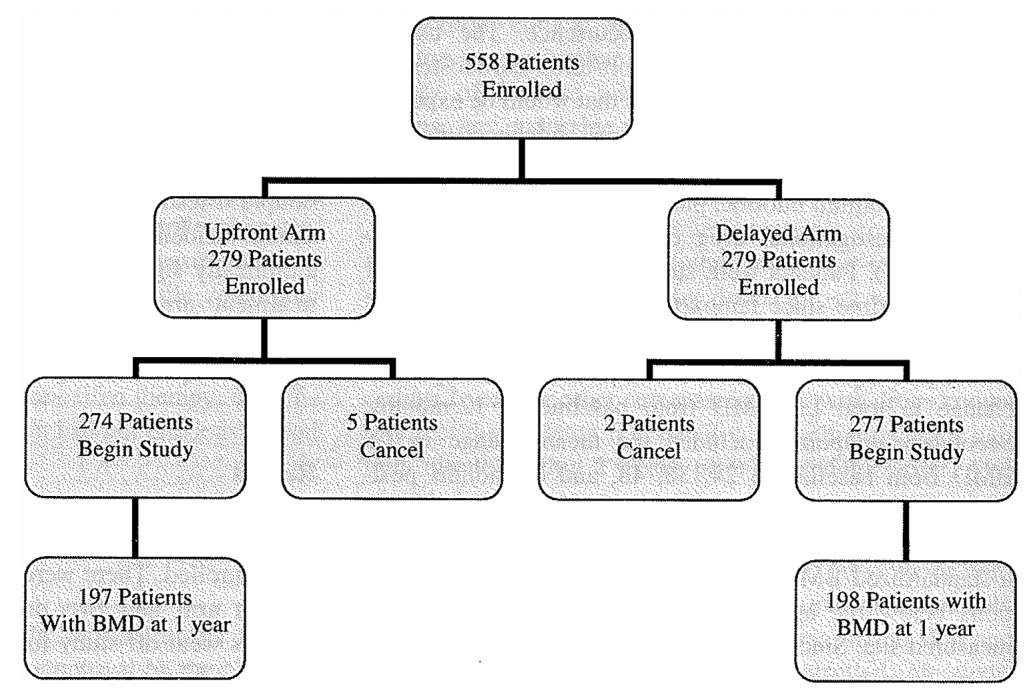

Fig. 1.

Patient enrollment diagram 
Table 1

Baseline patient characteristics

\begin{tabular}{|c|c|c|c|c|}
\hline & $\begin{array}{l}\text { Upfront } \\
(N=274)\end{array}$ & $\begin{array}{l}\text { Delayed } \\
(N=277)\end{array}$ & $\begin{array}{l}\text { Total } \\
(N=551)\end{array}$ & $P$ value \\
\hline Mean age & 59.2 & 59.6 & 59.4 & 0.75 \\
\hline \multicolumn{5}{|l|}{ Race } \\
\hline White & $269(98 \%)$ & $268(97 \%)$ & $537(97.5 \%)$ & 0.50 \\
\hline African American & $4(1.5 \%)$ & $6(2 \%)$ & $10(1.8 \%)$ & \\
\hline Asian & $1(0.4 \%)$ & $0(0 \%)$ & $1(0.2 \%)$ & \\
\hline American Indian & $0(0 \%)$ & $1(0.4 \%)$ & $1(0.2 \%)$ & \\
\hline Not Reported & $0(0 \%)$ & $1(0.4 \%)$ & $1(0.2 \%)$ & \\
\hline Unknown & $0(0 \%)$ & $1(0.4 \%)$ & $1(0.2 \%)$ & \\
\hline \multicolumn{5}{|l|}{ Performance score } \\
\hline 0 & $261(95 \%)$ & $263(95 \%)$ & $524(95 \%)$ & 0.87 \\
\hline 1 & $13(5 \%)$ & $14(5 \%)$ & $27(5 \%)$ & \\
\hline \multicolumn{5}{|l|}{ Baseline $\mathrm{T}$ score } \\
\hline$>-1 \mathrm{SD}$ & $152(55.5 \%)$ & $153(55 \%)$ & $305(55 \%)$ & 0.95 \\
\hline Between -1 and -2 SD & $122(44.5 \%)$ & $124(45 \%)$ & $246(45 \%)$ & \\
\hline \multicolumn{5}{|l|}{ Prior tamoxifen duration } \\
\hline$\underline{s}$ years & $61(22 \%)$ & $61(22 \%)$ & $122(22 \%)$ & 0.95 \\
\hline$>2$ years & $213(78 \%)$ & $216(78 \%)$ & $429(78 \%)$ & \\
\hline \multicolumn{5}{|l|}{ Time since tamoxifen } \\
\hline$<1$ year & $264(96 \%)$ & $267(96 \%)$ & $531(96 \%)$ & 0.98 \\
\hline$\geq 1$ year & $10(4 \%)$ & $10(4 \%)$ & $20(4 \%)$ & \\
\hline \multicolumn{5}{|l|}{ Prior chemotherapy } \\
\hline Yes & $190(69 \%)$ & $190(69 \%)$ & $380(69 \%)$ & 0.85 \\
\hline No & $84(31 \%)$ & $87(31 \%)$ & $171(31 \%)$ & \\
\hline
\end{tabular}

Breast Cancer Res Treat. Author manuscript; available in PMC 2014 January 30. 
Table 2

Lumbar spine BMD changes at 1 and 2 years

\begin{tabular}{llll}
\hline Variable $(\mathrm{g} / \mathrm{cm})$ & $\begin{array}{l}\text { Upfront } \\
(\boldsymbol{N}=\mathbf{2 5 3}), \\
\text { mean }\end{array}$ & $\begin{array}{l}\text { Delayed } \\
(\boldsymbol{N}=\mathbf{2 5 2}), \\
\text { mean }\end{array}$ & $\boldsymbol{P}$ value \\
\hline Baseline LS & 1.09 & 1.11 & 0.35 \\
1 year LS & 1.13 & 1.09 & 0.004 \\
LS change at 1 year & 0.04 & -0.02 & $<0.001$ \\
LS \% change at 1 year & $3.66 \%$ & $-1.66 \%$ & $<0.001$ \\
LS change at 2 years & 0.05 & -0.03 & $<0.001$ \\
LS \% change at 2 years & $4.94 \%$ & $-2.28 \%$ & $<0.001$ \\
\hline
\end{tabular}




\section{Table 3}

Femoral neck and total hip BMD

\begin{tabular}{clll}
\hline Variable (g/cm) & $\begin{array}{l}\text { Upfront } \\
(\boldsymbol{N = 2 0 8}), \\
\text { mean }\end{array}$ & $\begin{array}{l}\text { Delayed } \\
(\boldsymbol{N = 2 2 3}), \\
\text { mean }\end{array}$ & P value \\
\hline Baseline femoral neck & 0.87 & 0.86 & 0.35 \\
FN 1 year & 0.89 & 0.86 & 0.018 \\
FN change at 1 year & 0.02 & -0.01 & $<0.001$ \\
FN \% change at 1 year & $2.08 \%$ & $-0.09 \%$ & $<0.001$ \\
FN change at 2 years & 0.03 & -0.01 & $<0.001$ \\
FN \% change at 2 years & $3.36 \%$ & $0.54 \%$ & $<0.001$ \\
Baseline total hip & 0.95 & 0.94 & 0.71 \\
TH 1 year & 0.97 & 0.94 & 0.016 \\
TH change at 1 year & 0.01 & 0 & $<0.001$ \\
TH \% change at 1 year & $1.02 \%$ & $-1.41 \%$ & $<0.001$ \\
TH change at 2 years & 0.01 & -0.01 & $<0.001$ \\
TH \% change at 2 years & $1.22 \%$ & $-3.34 \%$ & $<0.001$ \\
\hline
\end{tabular}


Table 4

Incidence of a clinically meaningful $5 \%$ decline in BMD at 1 year

\begin{tabular}{ccccc}
\hline & $\begin{array}{l}\text { Upfront } \\
(\boldsymbol{N}=\mathbf{2 7 4})\end{array}$ & $\begin{array}{l}\text { Delayed } \\
(\boldsymbol{N}=\mathbf{2 7 7})\end{array}$ & $\begin{array}{l}\text { Total } \\
(\mathbf{N}=\mathbf{5 5 1})\end{array}$ & $\boldsymbol{P}$ value \\
\hline LS & & & & \\
No & $191(97 \%)$ & $157(79 \%)$ & $348(88 \%)$ & $<0.0001$ \\
Yes & $6(3 \%)$ & $41(21 \%)$ & $47(12 \%)$ & \\
FN & & & & \\
No & $142(92 \%)$ & $141(81 \%)$ & $283(86 \%)$ & 0.0057 \\
Yes & $13(8 \%)$ & $33(19 \%)$ & $46(14 \%)$ & \\
TH & & & & \\
No & $137(96 \%)$ & $111(79 \%)$ & $248(87 \%)$ & $<0.0001$ \\
Yes & $6(4 \%)$ & $30(21 \%)$ & $36(13 \%)$ & \\
\hline
\end{tabular}

Breast Cancer Res Treat. Author manuscript; available in PMC 2014 January 30. 


\section{Table 5}

Adverse events reported at $\geq 4 \%$ frequency from baseline to 6 months

\begin{tabular}{lccl}
\hline Adverse event & $\begin{array}{l}\text { Upfront } \\
(\boldsymbol{N}=\mathbf{2 6 7})\end{array}$ & $\begin{array}{c}\text { Delayed } \\
(\boldsymbol{N}=\mathbf{2 7 4})\end{array}$ & $\boldsymbol{P}$ value \\
\hline Fever & $14(5 \%)$ & $1(0 \%)$ & 0.0006 \\
Nausea & $24(9 \%)$ & $8(3 \%)$ & 0.0025 \\
Vomiting & $10(4 \%)$ & $1(0 \%)$ & 0.0054 \\
Back pain & $46(17 \%)$ & $35(13 \%)$ & 0.12 \\
Myalgia & $15(6 \%)$ & $9(3 \%)$ & 0.19 \\
Arthralgia & $24(9 \%)$ & $18(6 \%)$ & 0.29 \\
Limb edema & $4(1 \%)$ & $0(0 \%)$ & 0.42 \\
Hot flashes & $17(6 \%)$ & $20(8 \%)$ & 0.68 \\
\hline
\end{tabular}




\section{Table 6}

Adverse events reported at $\_4 \%$ frequency from baseline to 1 year

\begin{tabular}{llll}
\hline Adverse event & Upfront $(\boldsymbol{N = 2 6 7 )}$ & Delayed $(=\mathbf{2 7 4})$ & $\boldsymbol{P}$ value \\
\hline Fever & $18(6 \%)$ & $1(0 \%)$ & 0.0001 \\
Creatinine & $10(4 \%)$ & $3(1 \%)$ & 0.045 \\
Limb edema & $4(1 \%)$ & $0(0 \%)$ & 0.042 \\
Fatigue & $15(5 \%)$ & $6(2 \%)$ & 0.038 \\
Nausea & $29(11 \%)$ & $17(6 \%)$ & 0.048 \\
Vomiting & $10(4 \%)$ & $6(2 \%)$ & 0.29 \\
Hot flashes & $21(8 \%)$ & $27(10 \%)$ & 0.42 \\
Myalgia & $17(7 \%)$ & $14(5 \%)$ & 0.53 \\
Arthralgia & $34(13 \%)$ & $31(11 \%)$ & 0.59 \\
Back pain & $66(25 \%)$ & $64(23 \%)$ & 0.67 \\
\hline
\end{tabular}

